\title{
Austerity, sanctions, and the rise of food banks in the UK
}

\author{
Doctors are witnessing increasing numbers of patients seeking referrals to food banks in the United \\ Kingdom. Rachel Loopstra and colleagues ask, is this due to supply or demand?
}

\author{
Rachel Loopstra postdoctoral researcher ${ }^{1}$, Aaron Reeves senior research fellow ${ }^{1}$, David \\ Taylor-Robinson senior clinical lecturer in public health ${ }^{2}$, Ben Barr senior clinical lecturer in applied \\ public health ${ }^{2}$, Martin McKee professor of european public health ${ }^{3}$, David Stuckler professor of \\ political economy and sociology ${ }^{1}$
}

${ }^{1}$ Department of Sociology, Oxford University, Manor Road Building, Manor Road, Oxford OX1 3UQ, UK; ${ }^{2}$ Department of Public Health and Policy, University of Liverpool, UK; ${ }^{3}$ Faculty of Public Health and Policy, London School of Hygiene and Tropical Medicine London, UK

In the spring of 2014 the Trussell Trust, a non-governmental organisation that coordinates food banks in the United Kingdom, reported that it had distributed emergency food parcels to 913 138 children and adults across the UK in the previous year-seven times more than in 2011-12. ${ }^{1}$ In 2009-10 Trussell Trust food banks were operating in 29 local authorities across the UK; by 2013-14, the number had jumped to 251 (fig $1 \Downarrow$ ). Although soup kitchens have long operated in the UK, ${ }^{2}$ this rapid spread of food banks is a new phenomenon, raising concerns from the UK's Faculty of Public Health that "the welfare system is increasingly failing to provide a robust last line of defence against hunger." ${ }^{3}$ General practitioners have also raised concerns about patients seeking referrals to food banks. ${ }^{4}$ One recent survey of 522 GPs found that $16 \%$ had been asked for such referrals. ${ }^{5}$

What has caused the sudden rise in food banks is a topic of considerable debate. ${ }^{6}$ Some commentators argue that it has little to do with food insecurity but results from food charities expanding their operations. ${ }^{7}$ They argue that people are taking advantage of food made freely available ${ }^{8}$ By contrast, UK food charities claim that they provide emergency food aid in response to economic hardship and food insecurity. ${ }^{9}{ }^{10} \mathrm{~A}$ joint report from the Trussell Trust, the Church of England, and the charities Oxfam and Child Poverty Action Group found that food bank users were more likely to live in rented accommodation, be single adults or lone parents, be unemployed, and have experienced a "sanction," where their unemployment benefits were cut for at least one month. ${ }^{11}$
These contrasting views, alongside a review from the Department for Environment, Food, and Rural Affairs that voiced concerns about food insecurity, ${ }^{2}$ prompted the establishment of the All Party Parliamentary Inquiry into Hunger and Food Poverty. ${ }^{12}$ Its final report, released in December 2014, highlighted the lack of conceptual clarity on what food insecurity is and called for the development of a systematic monitoring system. ${ }^{13}{ }^{14}$ It also echoed concerns that economic hardship, austerity measures, and government sanctions could underlie the rise in emergency food aid. However, the inquiry's final report drew heavily on submissions from food charities, predominantly consisting of anecdotal evidence, some of which had been previously critiqued as self selected data ${ }^{15}$ and unrepresentative of the UK population. ${ }^{11}$ These food charities may also have potential competing interests to raise funds and expand operations.

We ask whether the rise in emergency food assistance is linked to economic hardship, austerity measures, and sanctioning or whether it is a result of food charities creating their own demand. To test these competing hypotheses we created a new dataset that links information on the Trussell Trust's food bank operations to budgetary and socioeconomic data from 375 UK local authorities from 2006-07 to 2013-14. The Trussell Trust does not represent the totality of charitable food provisioning in the UK, but it is the largest supplier. ${ }^{13}$ Although the trust's surveys on reasons for food bank use have considerable limitations, its data on food parcel distribution have been collected from all member food banks since 2006, making it, to our knowledge, the only data source that can represent and 
track the state of UK charitable food aid over time. We evaluate where food banks are opening and why emergency food distribution is rising.

\section{Where are food banks opening?}

The Trussell Trust operates on a "bottom-up" basis, whereby local Christian churches and community groups apply to the trust to open a food bank and then make a one-off donation for the purchase of the franchise and commit to nominal annual donations. ${ }^{16}$

We chose 2009 as the base year for our analysis, as the opening of new Trussell Trust food banks began to take off in this year, with 29 local authorities having food banks. From 2010 to 2013 food banks opened in 222 local authorities, leaving 124 local authorities without food banks.

First we tested whether the authorities in which food banks opened between 2010 and 2013 had greater economic hardship (unemployment rates), ${ }^{17}$ austerity measures (including both central and local government welfare cuts), ${ }^{18-21}$ or sanctioning rates $^{22}$ than those in which food banks did not open. We used lagged logistic regression models, as it would take time for a food bank to open in response to a local population's economic difficulties. All models were adjusted for the proportion of people identifying as Christian, ${ }^{23}{ }^{24}$ as Trussell Trust food banks are only initiated by Christian churches. The data supplements on thebmj.com provide the descriptive statistics and details of the statistical models and variables used in the analysis.

Food banks were more likely to open in local authorities with higher unemployment rates (table $1 \Downarrow$ ). A percentage point increase in unemployment increased the likelihood of a food bank opening in the subsequent year by 1.08 -fold (odds ratio $1.08,95 \%$ confidence interval 1.02 to 1.14 ). By contrast, the overall level of economic activity and share of the population reporting Christian faith were not associated with food banks opening.

Greater welfare cuts increased the likelihood of a food bank opening. Each $1 \%$ cut in central government spending on welfare benefits in a local authority increased the odds of a food bank opening within two years by 1.6 -fold (95\% CI 1.25 to 2.03 ). Similar magnitude cuts in local authority spending increased odds of opening in the next year by 1.07 -fold (95\% CI 1.03 to $1.11)$ and by a further 1.06 -fold in the year after that $(95 \% \mathrm{CI}$ 1.02 to 1.11). To put the magnitude of these associations in perspective, the estimated likelihood of a food bank opening in an area that did not experience a spending cut in either of the past two years was $14.5 \%$ (95\% CI $12.3 \%$ to $17.4 \%$ ). This figure tripled to $52.0 \%$ for a local authority that experienced a mean budget cut of $3 \%$ in welfare spending in both years $(95 \% \mathrm{CI}$ $32.6 \%$ to $72.1 \%$ ).

\section{Why are food banks distributing more food?}

Next we evaluated why food banks are providing more food. To access a Trussell Trust food bank people must obtain a referral voucher from a frontline care professional who is a "voucher holder." Each food bank establishes its own links with potential voucher holders, which can vary but typically include doctors, health visitors, social workers, Citizen's Advice Bureau workers, and police, who are asked to identify people in crisis and issue vouchers where appropriate. ${ }^{25}$ Individuals take their voucher to a food bank during opening hours and are provided with a parcel intended to contain enough food for the household to last three days. ${ }^{26}$
Between 2010 and 2013 the rate of food parcel distribution tripled, from about 0.6 to 2.2 per 100 population (Web Appendix A: table A1 in data supplement on thebmj.com). There was stark variation across local areas, ranging from $<0.1$ food parcels per 100 population in Torbay, Lichfield, and Wychavon to as high as eight parcels per 100 population in Eastbourne and Newcastle upon Tyne.

The increase in the number of people fed by the Trussell Trust has been attributed to greater availability of food banks within communities rather than an increased demand for food from food insecurity. ${ }^{8}$ To account for this possibility, we compared food parcel distribution between 2010 and 2013 in 251 local authorities with operating food banks using linear regression models. We adjusted for a local authority's capacity to provide food by accounting for the number of food banks and years of food bank operation.

We found that significantly more people were using food banks in local authorities that had greater numbers of food banks and in those that had food banks which had been operating for longer periods of time (table $2 \Downarrow$ ). One possible explanation is that it takes time for food banks to build relationships with the local care professionals who provide referrals.

Importantly, when controlling for the association with the capacity of food banks to provide food we still observed that greater central government welfare cuts, sanctioning, and unemployment rates were significantly associated with higher rates of food parcel distribution. Each $1 \%$ cut in spending on central welfare benefits was associated with a 0.16 percentage point rise in food parcel distribution ( $95 \%$ CI 0.10 to 0.22 ). Similarly, each $1 \%$ increase in the rate of benefit sanctions was associated with a significant increase of 0.09 percentage points (95\% CI 0.01 to 0.17 ) in the prevalence of food parcel distribution. In some of the most deprived areas of England, such as Derby, where sanction rates rose to $13 \%$ of benefit claimants in 2013, this equates to a substantial rise in food parcel distribution, to an additional one parcel for every 100 persons living in the area.

\section{Implications of rising food bank use}

More food banks are opening in areas experiencing greater cuts in spending on local services and central welfare benefits and higher unemployment rates. The rise in food bank use is also concentrated in communities where more people are experiencing benefit sanctions. Food parcel distribution is higher in areas where food banks are more common and better established, but our data also show that the local authorities with greater rates of sanctions and austerity are experiencing greater rates of people seeking emergency food assistance.

Utilisation data, such as the number of parcels distributed, are an imperfect measure of need. ${ }^{27}$ Food bank referrals are not always easy to obtain and, even now, provision is patchy. Our data also exclude families unwilling to use these food banks or those using food banks run by other agencies. ${ }^{10}$ Although Trussell Trust food banks constitute over half of food banks operating in the UK, total food bank usage is not consistently monitored. ${ }^{14}$ Thus, we have likely underestimated the true burden of food insecurity in the UK.

There is a clear need to develop better measures of food insecurity and the provision of emergency food that will capture the full extent of the problem in the UK. Although several nations use standardised survey instruments to monitor food insecurity, there is currently no national surveillance system in the UK. To our knowledge, the most recent epidemiological study of food insecurity for the whole of the UK was the 2004 
Low Income Diet and Nutrition study. ${ }^{28}$ This found that $29 \%$ of low income households had experienced food insecurity in the past month, defined as "the state of being without reliable access to a sufficient quantity of affordable, nutritious food." Future research is needed to investigate other factors that may influence emergency food aid, including rising food prices, energy costs and other costs of living, as well as further characteristics of food bank operations, such as operating hours, number of distribution sites, and the average distance to reach a food bank.

Physicians have key roles as advocates. In the current food bank system physicians are having to take on gatekeeper roles. ${ }^{5}$ According to statistics from the Trussell Trust, an estimated 27 000 frontline care professionals provided referrals in 2013-14. ${ }^{1}$ Rather than accept this situation, an alternative is to call for action on the root social and economic factors that trigger reliance on food banks.

Contributors and sources: RL and DS designed the research; $R L$ compiled the dataset with contribution from BB; RL and DS analysed the data with additional help from $A R ; R L$ wrote the first draft of the manuscript; all authors contributed to the interpretation of the results and the writing of the manuscript.

Competing interests: We have read and understood BMJ policy on declaration of interests and declare the following: $D S, A R$, and $R L$ are funded by a Wellcome Trust Investigator Award. DS is also funded by ERC Grant 313590-HRES. All authors have completed the ICMJE uniform disclosure form. The authors have no financial relationships with any organisations that might have an interest in the submitted work in the previous three years, no other relationships or activities that could appear to have influenced the submitted work.

Provenance and peer review: Not commissioned; externally peer reviewed.

1 The Trussell Trust. Latest foodbank figures top 900 000. Press release. 2014. www. trusselltrust.org/foodbank-figures-top-900000.

2 Lambie-Mumford H, Crossley D, Jensen E, Verbeke M, Dowler E. Household food insecurity in the UK: a review of food aid. Feb 2014. www.gov.uk/government/uploads/ system/uploads/attachment_data/file/283071/household-food-security-uk-140219.pdf.

3 Ashton JR, Middleton J, Lang T. Open letter to Prime Minister David Cameron on food poverty in the UK. Lancet 2014;383:1631.

4 BMA. Food banks take a bite from surgery resources. 9 May 2014. http://bma.org.uk/ news-views-analysis/news/2014/may/food-banks-take-a-bite-from-surgery-resources.

5 Matthews-King A. One in six GPs asked to refer a patient to a food bank in the past year. Pulse $2014 \mathrm{Feb} 18$. www pulsetoday co uk/news/practice-news/one-in-six-gps-asked-torefer-a-patient-to-a-food-bank-in-the-past-year/20005889.article\#.VNDbaU0qVGE.

6 Gentleman A. Food bank Britain: can MPs agree on the causes of poverty in the UK? Guardian 2014 Jul 4. www.theguardian.com/society/2014/jul/04/food-bank-britain-canmps-agree-causes-uk-poverty.
7 Fisher L. Christian charity hits back over Tory attacks on food banks. Guardian 2014 Apr 19. www theguardian com/society/2014/apr/19/david-cameron-food-banks-trussell-trusttory-split.

8 Williams Z. To Lord Freud, a food bank is an excuse for a free lunch. Guardian 2013 Jul 4. www.theguardian.com/commentisfree/2013/jul/04/lord-freud-food-banks.

9 Lambie-Mumford H. Food bank provision and welfare reform in the UK. Apr 2014. http:// sperideptshef.ac.uk/wp-content/uploads/2014/01/SPERI-British-Political-Economy-BriefNo4-Food-bank-provision-welfare-reform-in-the-UK pdf.

10 Cooper N, Purcell S, Jackson R. Below the breadline: the relentless rise of food poverty in Britain. Jun 2014. www.church-poverty.org.uk/breadline/read/belowbreadlinereport/ view.

11 Perry J, Williams M, Sefton T, Haddad M. Emergency use only: understanding and reducing the use of food banks in the UK. Nov 2014. http://policy-practice.oxfam.org.uk/publications/ emergency-use-only-understanding-and-reducing-the-use-of-food-banks-in-the-uk-335731.

12 All-Party Parliamentary Inquiry into Hunger and Food Poverty. Terms of reference. http: //foodpovertyinquiry.org/terms-of-reference/.

13 All-Party Parliamentary Inquiry into Hunger and Food Poverty. Feeding Britain: a strategy for zero hunger in England, Wales, Scotland, and Northern Ireland. 2014. https:// foodpovertyinquiry.files.wordpress.com/2014/12/food-poverty-feeding-britain-final.pdf.

14 Forsey A. An evidence review for the All-Party Parliamentary Inquiry into Hunger in the United Kingdom. 2014. https://foodpovertyinquiry.files.wordpress.com/2014/12/foodpoverty-appg-evidence-review-final.pdf.

15 Butler P. Government dismisses study linking use of food banks to benefit cuts. Guardian 2014 Nov 19. www.theguardian.com/society/2014/nov/19/cuts-benefit-changes-drivingup-use-food-banks-study.

16 Lambie-Mumford $\mathrm{H}$. The right to food and the rise of charitable emergency food provision in the United Kingdom [Thesis]. University of Sheffield, 2014. http://etheses. whiterose.ac. uk/7227.

17 Office for National Statistics. Nomis: official labour market statistics. www.nomisweb.co.

18 Department for Work and Pensions. Benefit expenditure by local authority from 2000-01 to 2013-14. www.gov.uk/government/collections/benefit-expenditure-tables.

19 Department for Communities and Local Government. Local authority revenue expenditure and financing. www.gov.uk/government/collections/local-authority-revenue-expenditureand-financing.

20 Scottish government. Scottish local government financial statistics, 2014. www. gov.scot/Topics/Statistics/Browse/Local-Government-Finance/PubScottishLGFStats.

21 Welsh government. Local authority revenue outturn expenditure, 2014. http://wales.gov. uk/statistics-and-research/local-authority-revenue-outturn-expenditure/?lang=en

22 National Statistics. Jobseekers allowance (JSA) sanctions-number of decisions. 2014. https://stat-xplore.dwp.gov.uk

23 National Records of Scotland. Census 2011. Religion by council area, Scotland, 2011 www.scotlandscensus.gov.uk/documents/censusresults/release2a/rel2asbfigure12.pdf.

24 Office for National Statistics. 2011 Census. Key statistics for local authorities in England and Wales. Dec 2012. www.ons.gov.uk/ons/rel/census/2011-census/key-statistics-forlocal-authorities-in-england-and-wales/index.html.

25 The Trussell Trust. UK foodbanks. 2014. www.trusselltrust.org/foodbank-projects.

26 Lambie $\mathrm{H}$. The Trussell Trust foodbank network: exploring the growth of foodbanks across the UK. Nov 2011. www.trusselltrust.org/resources/documents/Our\%20work/Lambie-( 2011)-The-Trussell-Trust-Foodbank-Network---Exploring-the-Growth-of-FoodbanksAcross-the-UK.pdf.

27 Lambie-Mumford H. "Every town should have one": emergency food banking in the UK $J$ Soc Policy 2013;42:73-89.

28 Nelson M, Erens B, Bates B, Church S, Bosher T. Low income diet and nutrition survey. Vol 3. Nutritional status, physical activity, economic, social and other factors. Food Standards Agency, 2007.

Accepted: 25 March 2015

Cite this as: BMJ 2015;350:h1775

(c) BMJ Publishing Group Ltd 2015 


\section{Key messages}

Expansion of food banks across the United Kingdom is unprecedented—-the number of local authorities with food banks operated by the Trussell Trust has risen from 29 in 2009-10 to 251 in 2013-14

This rise is associated with cuts to local authority spending and central welfare spending

Highest levels of food bank use have occurred where there have been the highest rates of sanctioning, unemployment, and cuts in central welfare spending

There is a need for strategic approach to address food insecurity in the UK, which should include monitoring and addressing the root social and economic drivers of this problem

\section{Tables}

\begin{tabular}{|c|c|c|}
\hline Socioeconomic factors & Odds ratio for food bank opening & $95 \% \mathrm{Cl}$ \\
\hline \multicolumn{3}{|c|}{ Each one percentage point higher unemployment rate } \\
\hline One year prior & $1.08^{*}$ & 1.02 to 1.14 \\
\hline \multicolumn{3}{|c|}{ Each $1 \%$ cut in central government welfare spending } \\
\hline One year prior & 1.16 & 0.95 to 1.41 \\
\hline Two years prior & $1.59 \dagger$ & 1.25 to 2.03 \\
\hline \multicolumn{3}{|c|}{ Each $1 \%$ cut in local authority welfare spending in the prior year } \\
\hline One year prior & $1.07 \dagger$ & 1.03 to 1.11 \\
\hline Two years prior & $1.06^{*}$ & 1.02 to 1.11 \\
\hline \multicolumn{3}{|c|}{$\begin{array}{l}\text { Each one percentage point higher rate of adverse sanction decisions } \\
\text { per claimant }\end{array}$} \\
\hline One year prior & 1.08 & 0.95 to 1.22 \\
\hline \multicolumn{3}{|c|}{ Each £1000 higher gross value added per capita } \\
\hline Current year & 1.02 & 0.74 to 1.39 \\
\hline One year prior & 0.99 & 0.73 to 1.36 \\
\hline \multicolumn{3}{|c|}{ Each one percentage point higher rate of Christian population } \\
\hline 2011 census year & 1.00 & 0.98 to 1.02 \\
\hline
\end{tabular}


Table 2| Determinants of food parcel distribution in 2010-13 in 251 local authorities with operating food banks (575 local authority years) Percentage point change in food bank $95 \% \mathrm{Cl}$ use per capita

Food bank characteristics

Each additional year of food bank operating in local authority $0.38 \ddagger$

\section{Socioeconomic factors}

Each one percentage point higher rate of adverse sanction decisions per $\quad 0.09^{\circ}$ claimant

\begin{tabular}{lll}
\hline Each one percentage point higher unemployment rate & $0.06 \dagger$ & 0.02 to 0.09 \\
\hline Each one percentage point cut in central government welfare spending & $0.16 \ddagger$ & 0.10 to 0.22 \\
\hline Each one percentage point cut in local authority welfare spending & -0.021 & -0.05 to 0.01 \\
\hline Each £1000 higher gross value added per capita & -0.01 & -0.01 to 0.002 \\
\hline Each one percentage point higher rate of Christian population & 0.01 & -0.003 to 0.03 \\
\hline
\end{tabular}

Confidence intervals based on standard errors clustered by local authority to reflect non-independence of sample units. ${ }^{*} \mathrm{P}<0.05, \dagger P<0.01, \ddagger \mathrm{P}<0.001$. 


\section{Figure}

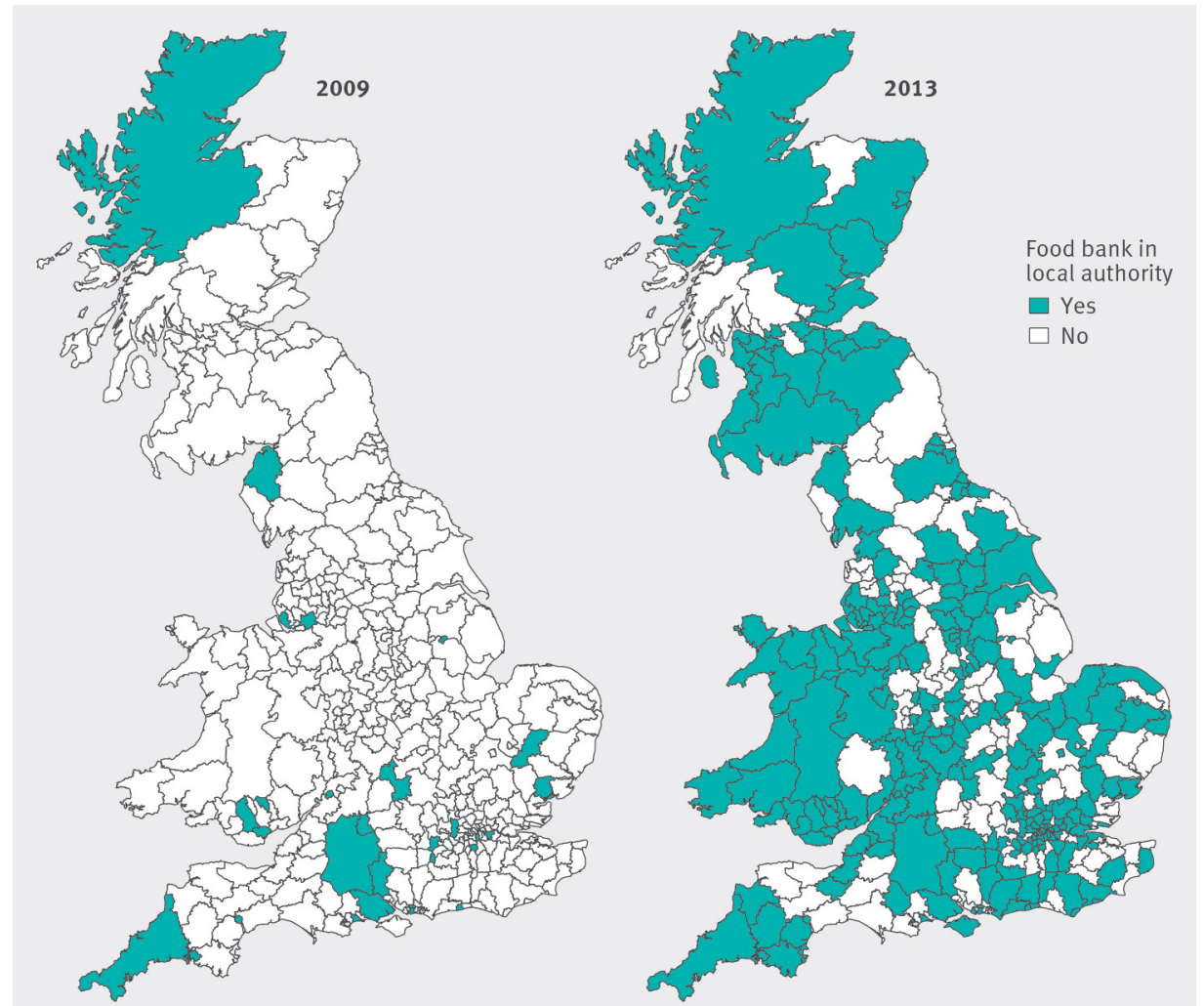

Trussell Trust food banks in local authorities in England, Scotland, and Wales in 2009 and 2013. Source: The Trussell Trust. 